\title{
Pengaruh Kepemimpinan dan Motivasi Kerja Terhadap Kepuasan Kerja
}

\author{
Franedy dan Carol Daniel Kadang \\ Program Studi Manajemen Fakultas Ekonomi \& Bisnis \\ Universitas Tarumanagara \\ Email: franedy1994@gmail.com
}

\begin{abstract}
This research aims to determine two purposes, there is an effect of leadership on employees' job satisfaction and then there is an effect of work motivation on employees' job satisfaction. The researchers took a total sample of 60 respondents. This research method uses SmartPLS and uses a causal method. The hypothesis testing conducted in this research that there is a positive significant effect of organizational culture on the employees' job satisfaction of PT. Triputra Cipta Karya. There is a positive significant effect of work motivation on the employees performance of PT. Triputra Cipta Kary in Tangerang.
\end{abstract}

Keywords: Leadership, Work Motivation, Job Satisfaction

Abstrak: Penelitian ini memiliki dua tujuan, yaitu untuk mengetahui pengaruh kepemipinan terhadap kepuasan kerja karyawan PT Triputra Cipta Karya dan selanjutnya untuk mengetahui pengaruh motivasi kerja terhadap kepuasan kerja karyawan PT Triputra Cipta Karya. Peneliti mengambil jumlah sampel sebanyak 60 responden. Metode penelitian ini menggunakan SmartPLS ,analisis jalur. Pengujian hipotesis yang dilakukan di dalam penelitian ini adalah terdapat pengaruh positif signifikan kepemimpinan terhadap kepuasan kerja karyawan PT. Triputra Cipta Karya. Terdapat pengaruh positif signifikan motivasi kerja terhadap kepuasan kerja karyawan PT. Triputra Cipta Karya.

Kata kunci: Kepemimpinan, Motivasi Kerja, Kepuasan Kerja

\section{LATAR BELAKANG}

Kepuasan kerja merupakan suatu hal yang perlu di perhatikan karna kepuasan kerja antara karyawan yang satu berbeda dengan yang lainya. banyak yang berpendapat bahwa kepuasan kerja itu pada kenyataannya sulit untuk di wujudkan, karna sering kali terjadi masalah kepada seseorang yang memiliki kedudukan yang tinggi tetepi merasa tidak puasa dengan hasil pekerjaanya, atau seseorang yang telah memilik gaji yang besar seringkali merasa tidak puas juga dengan hasil kerjanya. Factor yang mempengaruhi kepuasan kerja karyawan diantaranya adalah kepemimpinan dan motifasi.

Dalam suatu organisasi ,faktor kepemimpinan memegang peranan yang sangat penting karena pemimpin itu yang nantinya akan mengerakan dan mengarahkan organisasi dalam mengapai sebuah tujuan yang telah direncanakan, akan tetapi itu semua bukanlah suatu hal yang mudah, sebab seorang pemimpin di haruskan memahami semua perilaku karyawannya yang memiliki karakteristik yang bebeda-beda antara yang satu dengan yang lainya. Dapat dikatakan berhasil atau tidaknya pencapaian suatu organisasi ditentukan dari kualitas seorang pemimpinnya.

Selain faktor kepimpinan ada juga beberapa faktor yang dapat memberikan efek positif dalam meningkatkan kepuasan kerja pada karyawan, factor yang dimaksud adalah dengan cara memberikan motivasi kerja yang tepat kepada para karyawan. Dalam suatu perusahaan pemberian motivasi kerja yang tepat kepada karyawannya merupakan aspek yang sangat penting karna dapat meningkatkan kinerja kerja keryawan tersebut sehingga dapat meberikan 
kepuasan kerja karyawan. jika kepuasan kerja karyawan dapat terpenuhi maka kinerja yang di hasilkan karyawan tesebut akan lebih maksimal. Dalam memotivasi karyawan diharuskan memahami dengan cara apakah kita dapat memotivasi karyawan supaya karyawan tersebut dapat termotivasi tinggi dan dapat menimbulkan kepuasan kerja karyawan tersebut.

PT Triputra Citra Karya adalah sebuah perusahaan yang bergerak dibidang General Contractor dan Steel yang mempekerjakaan banyak karyawan. PT Triputra Cipta Karya benar-benar bergantung kepada prestasi dan pekerjaan dari para karyawannya dalam mencapai tujuan organisasi dan kesuksesan pekerja, sehingga PT Triputra Cipta Karya berusaha secara terus menerus selalu mencoba memberi kepuasan terhadap para karyawanya.

Salah satu upaya yang harus dilakukan PT Triputra Cipta Karya dalam memaksimalkan kepuasan kerja karyawan adalah dengan cara menerapkan kepemimpinan yang baik dan memberikan motivasi kerja yang tepat. Yang mana pemimpin juga harus mengetahui apakah kepemimpinan yang sudah di terpakan dan motivasi kerja terhadap karyawan berpengaruh terhadap kepuasan kerja karyawan.

\section{KAJIAN TEORI}

Manajemen sumber daya manusia adalah salah satu sebagian dari fungsi dalam sebuah perusahaan atau organisasi yang berfokus pada kegiatan rekrutmen, pengelolaan dan pengarahan untuk orang - orang yang bekerja dalam sebuah perusahaan tersebut. Divisi sumber daya manusia yang mengelola manajemen sumber daya manusia ini akan menyediakan pengetahuan (tentang perusahaan), perlatan yang di butuhkan, pelatihan, layanan administrasi, pembinaan, saran hukum, serta pengawasan dan manajemen talenta. selain itu, divisi ini memiliki tugas dan tanggung jawab untuk mengembangkan perusahaan dengan menerapkan seluruh nilai dan budaya perusahaan. Menurut Hasibun (2010) berpendapat bahwa sumber daya manusia adalah ilmu dan seni yang mengatur hubungan dan peranan tenanga kerja agar lebih efektif dan efisien membantu terwujudnya tujuan perusahaan, karyawan dan masyarakat. Menurut Raymond A.Noe al (2015) manajemen sumber daya masanusia, mengacu pada kebijkan, praktik-praktik, serta sistem yang mempengaruhi perilaku, sikap dan kinerja karyawan.sehingga banyak karyawan perusahaan menyebut konsep Manajemen sumber manusia sebagai bentuk praktik-praktik tentang manusia. strategi yang mendasari praktik tersebut perlu dipertimbangkan agar dapat memaksimalkan pengaruhnya terhadap kinerja perusahaan. Menurut Sadili Samsudin (2009) mengemukakan bahwa manajemen sumber daya manusia adalah ilmu dan seni yang mengatur unsur manusia (cipta, rasa dan karsa) sebagai aset suatu organisasi dengan cara memperoleh, mengembangkan dan memelihara tenaga kerja secara efektif dan efesien.

Kepemimpinan. Kepemimpinan adalah sebuah proses memimpin atau mempengaruhi sebuah kelmpok orang untuk mencapai sebuah tujuan dan misi misi yang memang sudah di rencanakan.kepemimpinan seseorang sangat mempengaruhi sebuah kelmpok untuk mendapatkan tujuan yang di inginkan bersama. (Moeheriono, 2012)

Motivasi Kerja. Motivasi Kerja dapat didefinisikan sebagai suatu kondisi atau hasrat seseorang yang dapat mendorong mereka untuk melakukan sebuah perbuatan atau perubahan dalam sebuah pekerjaan yang nantinya akan dapat merubah seseorang mencapai sebuah tujuan yang di inginkan. (Malthis \& Jackson, 2011)

Kepuasan Kerja. Kepuasan kerja adalah suatu perasaan yang mengambarkan sikap menyenangkan atau sikap positif terhadap kepuasan yang di kerjakan dan sebagai hasil dari evaluasi terhadap pekerjaan yang mereka kerjakan. (Priansa, 2014) 
Kaitan antara kepempinan terhadap kepuasan kerja. Secara teoritis kepuasan kerja merupakan sikap, penilaian atau perasaan karyawan terhadap pekerjaannya dan berhubungan dengan lingkungan kerja, jenis pekerjaan, hubungan antar teman kerja dan hubungan sosial ditempat kerja (Koesmono, 2005). Sedangkan kepemimpinan merupakan upaya mempengaruhi banyak orang melalui komunikasi untuk mencapai tujuan, cara mempengaruhi orang dengan perintah atau petunjuk, tindakan yang membuat orang lain bertindak atau merespons dan menimbulkan perubahan positif, kekuatan dinamis penting yang memotivasi dan mengkoordinasikan organisasi dalam rangka mencapai tujuan, kemampuan untuk menciptakan rasa percaya diri dan dukungan diantara bawahan agar tujuan organisasi dapat tercapai adalah konsep kepemimpinan menurut Durbin (2005).

Kaitan antara kepemimpinan terhadap kepuasan kerja. Torang (2012) menyatakan bahwa motivasi kerja merupakan proses pemberian dorongan pada anak buah supaya anak buah dapat berkerja sejalan dengan batasan yang diberikan guna mencapai tujuan organisasi optimal. Motivasi adalah energi yang menggerakan individu untuk berusaha mencapai tujuan yang diharapkan ( Sulistiyani dan Rosidah, 2009).

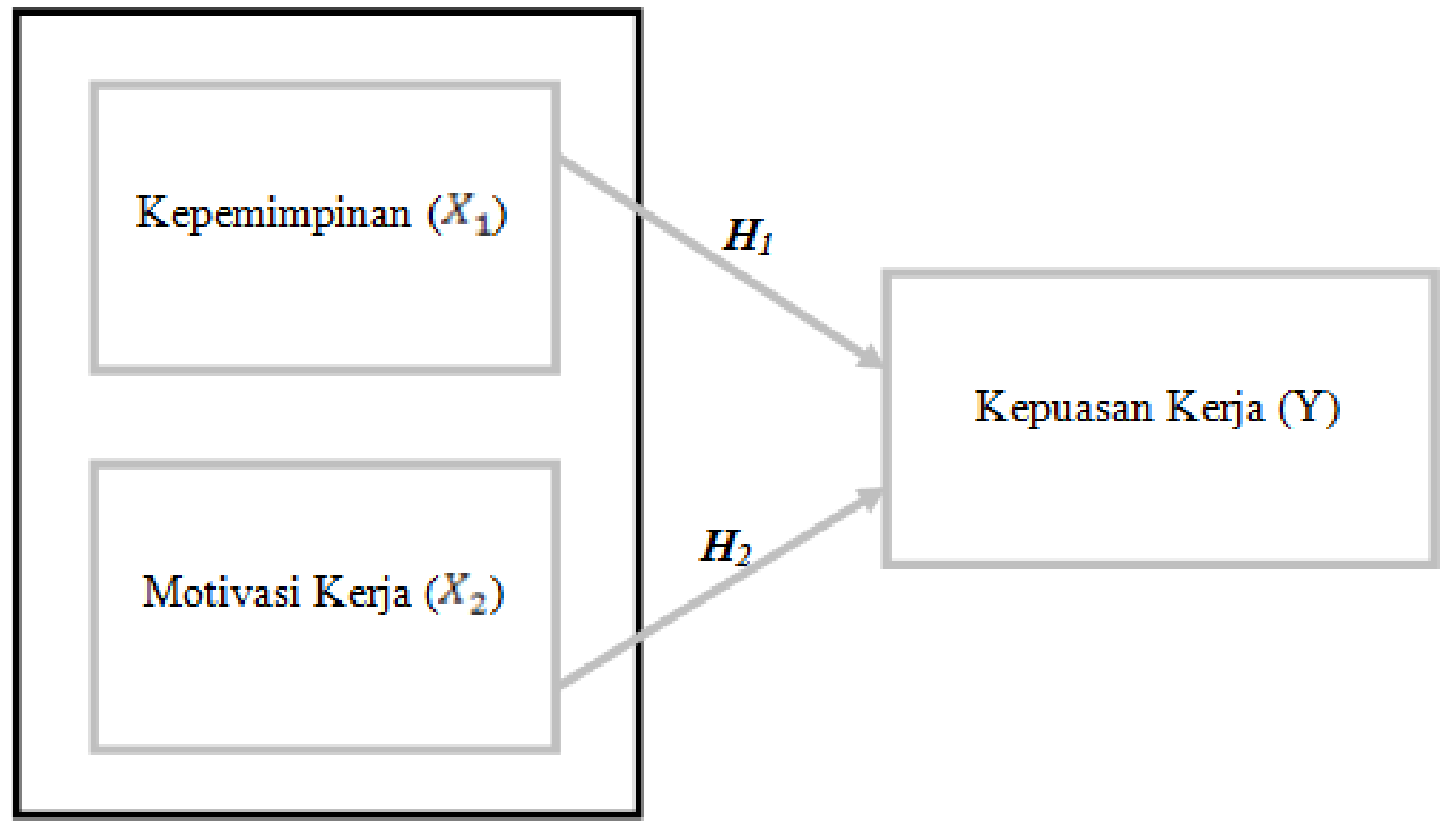

Gambar 1. Kerangka pemikiran

Berdasarkan pola gambar 1, maka didapatkan hipotesis berikut ini:

H1 : Kepemimpinan mempengaruhi secara positif dan signifikan terhadap kepuasan kerja.

$\mathrm{H} 2$ : Motivasi kerja mempengaruhi secara positif dan signifikan terhadap kepuasan kerja.

\section{METODOLOGI}

Dalam metode penelitian, terlebih dahulu harus menentukan metode apa yang ingin digunakan dalam penilitian ini,karena hal ini merupakan langkah-langkah yang harus dipikirkan terlebih dahulu.metode penelitian pendekatan kuantitatif berbentuk asosiatif sangat tepat digunkan dalam penelitian. Asosiatif adalah metode yang digunakan untuk menghubungan anatara variabel yang satu dengan variabel yang lainya. 
Menurut Sugiyono (2016) mendifinisikan penelitian asosiatif merupakan penelitian yang bertujuan megetahui ada tidaknya kaitan antara variabel yang satu dengan variabel lainya anatra variabel bebas terhadap variabel terkait dan seberapa eratnya pengaruh hubungan serta berarti atau tidaknya pengaruh hubungan variabel itu.variabel bebas dalam peneitian ini adalah pengaruh kepemimpinan (X1) dan motivasi kerja (X2), kemudian variabel terkaitnya adalah kepuasam kerja karyawan (Y).subjek yang akan dilakukan dalam penelitin ini adalah karyawan yang bekerja pada PT Triputra Cipta Karya.

Ukuran sampel dalam penelitian ini sebesar 60 responden dimana data dikumpulkan dengan melaksanakan survei menggunakan kuesioner dengan google form, pada subjek penelitian yakni karyawan PT Triputra Cipta Karya. Profil responden pada penelitian ini terdiri dari 5 kategori, yang mana dari 60 responden yang berpartisipasi, berdasarkan jenis kelamin, mayoritas adalah pria 55 orang (92\%), dan berdasarkan usia, mayoritas adalah berusia di antara 20-30 tahun 21 orang (35\%), dan terkahir berdasarkan pendidikan terkahir, mayoritas adalah berpendidikan terakhir SD sebanyak 19 orang $(31,7 \%)$, berdasarkan masa kerja, mayoritas masa karyawan di antara 6 tahun sampai 10 tahun sebanyak 28 orang (47\%).

Dalam melakukan sebuah penelitian langkah pertama yang perlu dilakukan dalam melaksanakan suatu penelitian adalah menentukan populasi terlebih dahulu.Menurut Sugiono (2016), populasi adalah wilayah generalisasi yang terdiri dari objek dan subjek yang memiliki karakteristik dan kualitas tertentu yang dipilih oleh peneliti untuk dipelajari dan kemudian di cari kesimpulanya.populasi dalam penelitian ini adalah karyawan PT.Triputra Cipta Karya yang berada di tangerang tahun 2019 dengan jumlah sampel karyawan 60 orang.

Sampel sepenuhnya diambil dari populasi, artinya peneliti tidak akan mendapatkan sempel jika tidak adanya populasi.sampel adalah metode yang digunakan untuk mengambil dan memilih sejumlah individu dari elmen populasi untuk digunakan sebagai sampel mewakili dari populasi itu.Menurut Sugiyono (2011) mendifinisikan sampel adalah bagian dari jumlah dan karakteristik yang dimiliki oleh populasi itu.Jumlah sampel ini di tentukan dengan mengunakan taknik sampling dan menurut Margono (2004) menjelaskan taknik sampling adalah cara untuk menentukan sampel yang jumlahnya sesuai dengan ukuran yang nanti datanya akan dijadikan sumber data sebenernya.Pada hal ini populasi yang di ambil adalah PT.Triputra Cipta Karya yang 60 oarang karyawan dengan metode kuisioner.

Variabel dan jumlah pernyataan yang digunakan dan yang akan diolah datanya dalam penelitian ini, tersaji dalam tabel 1 berikut ini:

1. Ukuran sampel yang layak dalam penelitian seharusnya antara 30 sampai dengan 500 sampel.

2. Apabila sampel dibagi dalam katagori (pria-wanita,pegwai negri -swasta dan lain lain.) maka harus diambil minimum 30 sampel setiap katagorinya.

3. Dimana dalam penelitian analisis dengan multivariate (kolerasi atau regresi ganda misalnya), maka seharusnya jumlah anggota sampel minimal 10 kali dari jumlah variabel yang diteliti.

4. Untuk penelitian experiman yang sederhana, yang memakai kelompok experimen dan kelompokan kontrol, maka jumlah angota sampel masing - masing 10 sampai 20 .

Tabel 1. Konstruk penelitian

\begin{tabular}{|l|l|l|}
\hline No & Variabel & Pernyataan \\
\hline 1 & Kepemimpinan & 8 \\
\hline 2 & Motivasi Kerja & 8 \\
\hline 3 & Kepuasan Kerja & 8 \\
\hline
\end{tabular}




\section{HASIL UJI STATISTIK}

Uji validitas. Adapun nilai corrected item - total correlation yang dihasilkan oleh kalkulasi data adalah sebesar diatas 0,3 maka dinyatakan bahwa seluruh pernyataan yang digunakan dalam penelitian ini adalah valid.

Uji reliabilitas. Adapun nilai cronbach's Alpha yang dihasilkan oleh kalkulasi data adalah sebesar diatas 0,6 maka dinyatakan bahwa variabel yang digunakan dalam penelitian adalah reliabel.

Uji asumsi analisis data. Berdasarkan olah data yang telah dilakukan, hasilnya dapat digunakan untuk menjawab hipotesis pada penelitian ini. Uji hipotesis pada penelitian ini dilakukan dengan melihat nilai T-Statistics dan nilai P-Values. Hipotesis penelitian dapat dinyatakan diterima apabila nilai P-Values $<0,05$. Berikut ini adalah hasil uji hipotesis yang diperoleh dalam penelitian ini:

Tabel 2. Hasil Pengujian Hipotesis

\begin{tabular}{|l|l|l|l|l|l|}
\hline & $\begin{array}{l}\text { Original } \\
\text { Sample }(\text { O) }\end{array}$ & $\begin{array}{l}\text { Sample } \\
\text { Mean }(M)\end{array}$ & $\begin{array}{l}\text { Standard } \\
\text { Deviation } \\
(\text { STDEV })\end{array}$ & $\begin{array}{l}\text { T Statistics } \\
(\text { JO/STDEV })\end{array}$ & P Value \\
\hline $\begin{array}{l}\text { Kepemimpinan } \\
\rightarrow \quad \text { Kepuasan } \\
\text { Kerja }\end{array}$ & 0.424 & 0.446 & 0.124 & 3.425 & 0.001 \\
\hline $\begin{array}{l}\text { Motivasi Kerja } \\
\rightarrow \quad \text { Kepuasan } \\
\text { Kerja }\end{array}$ & 0.536 & 0.519 & 0.118 & 4.536 & 0.0001 \\
\hline
\end{tabular}

\section{DISKUSI}

Hipotesis 1, yang dilakukan menggunakan software SmartPLS 3.00 menunjukkan nilai signifikansi variabel budaya organisasi adalah 0,001 (lebih kecil dari $\alpha=5 \%$ ). Oleh karena itu disimpulkan bahwa variabel budaya organisasi memiliki pengaruh positif terhadap kinerja karyawan dengan tingkat keyakinan 95\%. Hasil penelitian ini sejalan dengan (Koesmono \& Durbin, 2005)

Hipotesis 2, Untuk variabel motivasi kerja diperoleh nilai signifikansi sebesar 0,0001 yang berarti signifikan $<0,05$. Oleh karenanya dapat disimpulkan bahwa motivasi kerja memiliki pengaruh positif signifikan terhadap kepuasan kerja dengan tingkat keyakinan 95\%. ( Sulistiyani \& Rosidah, 2009).

\section{KESIMPULAN}

Hasil dari penelitian ini sesesuai dengan hasil penelitian Torang (2012), Sulistiyani dan Rosidah (2009) yang menunjukkan motivasi sangat penting diberikan kepada karyawan agar dapat mengerjakan tugas yang diberikan dengan sebaik mungkin. Motivasi juga berpengaruh besar terhadap kepuasan kerja karyawan yang tidak diberi motivasi atau dorongan untuk bekerja maka tidak akan mencapai target yang telah ditentukan, dalam hal ini karyawan menjadi tidak puas dengan hasil kerja yang telah di kerjakan. Keterbatasan penelitian ini adalah responden yang digunakan hanya dalam ruang lingkup karyawan pada PT. Tripitra Cipta Karya di Tanggeran sehingga hasil penelitian ini tidak dapat digeneralisasikan. Hasil 
penelitian mungkin akan berbeda jika dilakukan di tempat lain. Dan dalam penelitian ini peneliti hanya menggunkan dua variabel yang mempengaruhi kepuasan kerja yaitu kepemimpinan dan motivasi kerja, sedangkan masih banyak variabel lain yang mempengaruhi kepuasan kerja. Maka disarankan agar bagi akademisi, menambah beberapa variabel independen baru yang berpengaruh terhadap kepuasan kerja.

\section{DAFTAR PUSTAKA}

Noe, Raymond A., Hollenbeck, John R., Gerhart, Barry, Wright, Patrick M., (2014). Manajemen Sumber Daya Manusia : Mencapai Keunggulan Bersaing, Edisi 6 Buku 1, Alih Bahasa : David Wijaya, Salemba Empat, Jakarta.

Samsudin, Sadili, 2009, Manajemen Sumber Daya Manusia, Bandung: CV. Pustaka Setia.

Robbins, P. Stephen dan Mary Coulter. 2010. Manajemen, diterjemahkan oleh Bob Sabran, Wibi Hardani. Erlangga:Jakarta.

Wukir. (2013). Manajemen Sumber Daya Manusia dalam Organisasi Sekolah. Yogyakarta: Multi Presindo.

Abdillah, W. \& Hartono, J. (2015). Partial Least Square (PLS): Alternatif Structural Equation Modeling (SEM) dalam Penelitian Bisnis.Yogyakarta: C.V Andi Offset.

Arikunto, Suharsimi. (2006). Prosedur Penelitian. Jakarta : Rineka Cipta

Dessler, Gary. (2015). Human Resources Management. 14th edition. Harlow: Pearson Education Limited

Azar, M. \& Shafighi, A. A., (2013). The Effect of Work Motivation on Employees' Job Performance. International Journal of Academic Research in Business and Social Sciences. Vol 3 No 9.

Hussein, A. S., (2015). Penelitian Bisnis dan Manajemen Menggunakan Partial Least Square (PLS) dengan smartPLS 3.0. Universitas Brawijaya.

Lloyd L. Byars, Leslie W. Rue. (2011). Human Resources Management. 10th edition. New York: Mcgraw-Hill

Mejia, R., Gomez, D.B. \& Balkin, R.L.C. (2004). Managing human resources. New Jersey: Pearson Prentice Hall.

Mondy, R. Wayne. Joseph J. Martocchio. (2016). Human Resources Development. 14th edition. Harlow: Pearson Education Limited

Olobatuyi, Moses E. 2006. A User's Guide to Path Analysis. Maryland: University Press of America

Paais, Maartje. (2018). Effect of Work Stress, Organization Culture and Job Satisfaction toward employee performance in Bank Maluku. Academy of Strategic Management Journal. Volume 17, Issue 5

Prastyo Eko, et al. (2016). Pengaruh Motivasi, Kepuasan, dan Lingkungan kerja terhadap Kinerja Karyawan. Journal of Management Vol.02 No.02, Maret

DR. Yazdanifar, Rashad. (2016). The Impact of Transactional Leadership Style on Employees' Job Satisfaction and How to Sustain the Employees' Motivation

M. L. Voon., M. C. Lo., K. S. Ngui., N. B. Ayob. (2011) The Influence of Leadership Style on Employees' Job Satisfaction in Public Sector Organizations in Malaysia

Suryana, Nana., Hearani, Siti., Taba, Idrus Muhammad. (2012). Pengaruh Kepemimpinan dan Motivasi Kerja Terhadap Kepuasan Kerja Karyawan dan Kinerja Perusahaan

Fatimah, Rossyana., Wahyuni, Ida., Widjasena, Baju. (2014). Pengaruh Kepemimpinan dan Motivasi Kerja Terhadap Kepuasan Kerja Perawat Rawat Jalan Rumah Sakit Islam Harapan Anda Tegal

Wibowowati, Ida Yanuar. (2016). Pengaruh Kepemimpinan dan Motivasi Kerja Terhadap Kepuasan Kerja pada Home Industri Home Bakery 
Wirda, Fisla. \& Azna, Tuti. (2015). Pengaruh Gaya Kepemimpnan Situasional dan Motivasi Kerja terhadap Kepuasan Kerja Karyawan Politeknik Negeri Padang

Brahmasari, Ayu Ida. \& Suprayetno, Agus. (2017). Pengaruh Motivasi Kerja, Kepemimpinan, dan Budaya Organisasi Terhadap Kepuasan Kerja Karyawan serta Dampaknya pada Kinerja Perusahaan

Kusumawati, Ratna. (2010). Pengaruh Organisasi dan Gaya Kepemimpinan Terhadap Kepuasan Kerja untuk Meningkatkan Kinerja Karyawan

Prof. H. Ghozali, Imam. (2014). Structural Equation Modelling. Edisi 4. Semarang: Universitas Diponegoro

Prof DR. Wibowo SE, M.Phil. (2014). Manajemen Kinerja. Jakarta: PT Rajagrafindo Persada.

Prof DR. Wibowo SE, M.Phil. (2016). Manajemen Kinerja. Edisi ke lima. Jakarta: Rajawali Pers.

Ryani Dhyan Parashakti, et al. (2017). Determinants of Employee's Discipline and Motivation: Evidence from Banks in Indonesia. International Journal of Economic Perspectives. Volume 11, Issue 1

Sofiyanti, Neneng. Achmad Nawawi. (2017). Pengaruh Disiplin dan Motivasi Kerja Terhadap Kinerja Pegawai Satuan Polisi Pamong Praja (Satpol PP) Kabupaten Karawang. Buana Ilmu Vol. 1, No. 2, Mei

Sugiyono. 2006. Metode Penelitian Bisnis. Edisi ke 9. Bandung: Penerbit AlfaBeta Uma Sekaran, Roger Bougie. 2016. Research Method for Business. 7th edition. Chicester: Wiley

Tanto Wijaya, Fransisca Andreani. (2015). Pengaruh Motivasi dan Kompensasi terhadap Kinerja Karyawan pada PT Sinar Jaya Abadi Bersama. Program Manajemen Bisnis, Program Studi Manajemen, Universitas Kristen Petra. AGORA Vol. 3, No. 2

Abdillah, Willy dan Jogianto. (2015). Partial Least Square (PLS) - Alternatif Structural Equation Modeling (SEM) dalam Penelitian Bisnis. Yogyakarta: Penerbit Andi.

Andini. (2006). Pengaruh Kepuasan Kerja dan Strs Kerja Terhadap Turnover Intention pada Karyawan Hotel Holiday Inn Express. E-Jurnal Manajemen Unud, Vol. 6, No. 10

Aritonang, R, Lerbin R. (2009). Penelitian Pemasaran. Edisi Pertama. Jakarta: Universitas Tarumanegara..

Hasibuan, Malayu, S.P. (2011). Manajemen Sumber Daya Manusia (Edisi Revisi). Jakarta: Bumi Aksara

Riduwan, \& Kuncoro, E. Achmad. (2013). Cara Mudah Menggunakan dan Memaknai Path Analysis (Analisis Jalur). Bandung: Alfabeta.

Rivai, Mulyadi, Deddy. (2012). Kepemimpinan dan Organisasi. (Cetakan ke-9). Jakarta: PT. Rajagrafindo Persada.

Rivai, Venithal \& Ella, Jauvani, Sagala. (2010). Manajemen Sumber Daya Manusia Untuk Perusahaan. Edisi Kedua. Jakarta.

Spector. (1997). Job Stress and Job Satisfaction Among the Managerial Personnel of Textile Industry. Sumedha Journal of Management, Vol.6, Iss. 3, 65-74.

Sugiyono. (2012). Metode Peneltian Bisnis. Alfabeta. Bandung.

Sugiyono. (2013). Metode Penelitian Bisnis Pendekatan Kuantitatif, Kualitatif, dan R \& D. Bandung: Alfabeta.

Sugiyono. (2014). Metode Penelitian Bisnis Pendekatan Kuantitatif, Kualitatif, dan R \& D. Bandung: Alfabeta. 